\title{
Comparison on Phytochemical and Physico-Chemical Parameters of Ocimum sanctum Linn Grown in Different Locations of Sri Lanka
}

H. R. D. Fonseka ${ }^{1 *}$, L. D. A. M. Arawwawala ${ }^{2}$, W. M. S. S. K. Kulathunga ${ }^{3}$

\author{
${ }^{1}$ Ayurveda Teaching Hospital, Borella, Colombo 08, Sri Lanka \\ ${ }^{2}$ Industrial Technology Institute, Bauddhaloka Mawatha, Colombo 07, Sri Lanka \\ ${ }^{3}$ Department of Swasthavritta, Institute of Indigenous Medicine, University of Colombo, Rajagiriya, Sri Lanka
}

DOI: $10.36348 /$ sijtcm.2020.v03i07.005 $\quad$ | Received: 17.07 .2020 | Accepted: 24.07 .2020 | Published: 28.07 .2020

*Corresponding author: Dr. H. R. D. Fonseka

\section{Abstract}

Objectives: To compare the phyto-chemical and physico-chemcial differences between green leaves monotype $\left(\mathrm{MT}_{1}\right)$ and purple leaves monotypes $\left(\mathrm{MT}_{2}\right)$ of Ocimum sanctum Linn grown in selected provinces of Sri Lanka. Methods: Essential oil was extracted by hydro-distillation using Clevenger type apparatus and analyzed by Gas Chromatography technique. Physico-chemical investigations were done according to WHO guidelines. Results: Highest amount of essential oil content was present for both $\mathrm{MT}_{1}$ and $\mathrm{MT}_{2}$ of $O$. sanctum collected from Southern Province. Moreover, methyl eugenol was present in $O$. sanctum in a range of $0.2-66 \%$ and compared to the $\mathrm{MT}_{1}$ methyl eugenol content was higher in $\mathrm{MT}_{2}$ of $O$. sanctum collected from all selected provinces. The highest percentage of eugenol was contained in $\mathrm{MT}_{2}$ of $O$. sanctum and there is no significant dependency of the location. Further, it is very interesting to note that percentages of germacrene- D and $\beta$-elemene were both higher in $\mathrm{MT}_{2}$ of $O$. sanctum in WP and SP respectively. However, there was no significant difference in terms of total ash or water soluble ash or acid insoluble ash between $\mathrm{MT}_{1}$ and $\mathrm{MT}_{2}$ collected from four provinces of Sri Lanka. Conclusion: Overall results revealed that $\mathrm{MT}_{2}$ of $O$. sanctum collected from SP is more versatile in terms of oil content and chemical constituents.

Keywords: Methyl Eugenol, Ocimum sanctum Linn, Physico-chemical parameters, Sri Lanka.

Copyright @ 2020: This is an open-access article distributed under the terms of the Creative Commons Attribution license which permits unrestricted use, distribution, and reproduction in any medium for non-commercial use (NonCommercial, or CC-BY-NC) provided the original author and source are credited.

\section{INTRODUCTION}

Ocimum sanctum Linn (Family: Lamiaceae) is commonly known as Holy Basil or Tulsi and used not only in Ayurveda and Siddha medicines but also in Greek, Roman and Unani systems of medicine. In traditional system of medicine, different parts including leaves, stem, flower, root, seeds and even whole plant of $O$. sanctum have been recommended for the treatment of bronchitis, malaria, diarrhea, dysentery, skin disease, arthritis, eye diseases and insect bites [1, 2]. O. sanctum is grown in Asian countries including India, Pakistan, Bangladesh and Sri Lanka. It is a shrub which grows to a height of $50-60 \mathrm{~cm}$ and has typical aromatic smell. It has simple opposite green or purple leaves. Leaves are elliptic-oblong, obtuse or acute, entire or serrate, pubescent on both sides, minutely gland - dotted, base obtuse or acute. The Tulsi flowers are small having purple to reddish color, present in small compact clusters on cylindrical spikes [3-5]. As home remedies, a paste of $O$. sanctum leaves is used to reduce pain and inflammation, heal skin rashes, ring worm affected areas and insect bites, get rid of acne and pimple. Fresh $O$. sanctum juice is mixed with ginger and honey, help to reduce cough and cold. Regular consumption of $O$. sanctum leaves help to control diabetes and blood cholesterol [6]. Taxonomy of $O$. sanctum given below:

$\begin{array}{ll}\text { Kingdom } & \text { : Plantae } \\ \text { Sub kingdom } & \text { : Tracheobionta } \\ \text { Superdivision } & \text { : Spermatophyta } \\ \text { Division } & \text { : Magnoliophyta } \\ \text { Class } & \text { : Magnoliopsida } \\ \text { Subclass } & \text { : Asteridae } \\ \text { Order } & \text { : Lamiales } \\ \text { Family } & \text { : Lamiaceae } \\ \text { Genus } & \text { : Ocimum } \\ \text { Species } & \text { : O. sanctum }\end{array}$

$O$. sanctum is rich in phytochemicals such as oleanolic acid, ursolic acid, rosmarinic acid,eugenol, carvacrol, linalool, $\beta$ caryophyllene (about 8\%). The essential oil of O.sanctum leaves consists mostly of eugenol $(\sim 70 \%) \beta$-elemene $(\sim 11.0 \%), \beta$-caryophyllene $(\sim 8 \%)$ and germacrene $(\sim 2 \%) \quad[6,7]$. Scientific investigations have shown antioxidant, 
immunomodulatory, antipyretic, anticancer, chemopreventive, radiopreventive, antihypertensive, antidiabetic, hepatoprotective, memory enhancing, antioxidant, analgesic, anti-inflammatory and antimicrobial activities $[6,8,9]$.

It is available as a weedy plant in Sri Lanka and locally known as Heenmadurutalā or Madurutalā. A few researches have been carried out to investigate the properties of $O$. sanctum grown in Sri Lanka. Secondary metabolites [10] and essential oil composition [11] of $O$. sanctum were investigated using $O$. sanctum grown in Sri Lanka. However, two monotypes of $O$. sanctum (Plate-1) are present in the country: plants with green leaves monotypes $\left(\mathrm{MT}_{1}\right)$ and purple leaves monotypes $\left(\mathrm{MT}_{2}\right)$. It is well known that types and amounts of secondary metabolites of plants depend on their environmental conditions. Therefore, an attempt was made to compare the phyto-chemical and physico-chemcial differences between $\mathrm{MT}_{1}$ and $\mathrm{MT}_{2}$ of $O$. sanctum grown in selected provinces [Western province (WP), North Central province (NCP) Southern province (SP) and North province (NP)] of Sri Lanka.

\section{MATERIALS AND METHODS \\ Plant Materials}

O. sanctum plants (both $\mathrm{MT}_{1}$ : with green leaves and $\mathrm{MT}_{2}$ : with purple leaves) were collected from WP $\left(6.9016^{\circ} \mathrm{N}, 80.0088^{\circ} \mathrm{E}\right), \mathrm{NCP}\left(8.1996^{\circ} \mathrm{N}\right.$, $\left.80.6327^{\circ} \mathrm{E}\right), \operatorname{SP}\left(6.2374^{\circ} \mathrm{N}, 80.5438^{\circ} \mathrm{E}\right)$ and $\mathrm{NP}$ $\left(8.8855^{\circ} \mathrm{N}, 80.2767^{\circ} \mathrm{E}\right)$ of Sri Lanka at flowering stage. The plants were identified and authenticated by the Curator of National Herbarium, Royal Botanical Gardens, Peradeniya, Sri Lanka. Voucher specimens of each type of $O$. sanctum were deposited in the Institute of Indigenous Medicine, University of Colombo, Rajagiriya, Sri Lanka. The leaves of both $\mathrm{MT}_{1}$ and $\mathrm{MT}_{2}$ were separated, washed, shade dried, cut into small pieces and kept in air tight containers separately labeled as WP, NCP, SP and NP until used.

\section{Extraction of Essential Oil}

O. sanctum leaves $(500 \mathrm{~g})$ of each $\mathrm{MT}_{1}$ and $\mathrm{MT}_{2}$ were added to a round bottom, fixed with a Clevenger-type apparatus and essential oil was obtained separately by hydro distillation. The extracted volatile oil was dried over anhydrous sodium sulphate and stored in sealed vials at $4{ }^{\circ} \mathrm{C}$ until analysis. The yield of the oil was calculated based on dry weight of plant materials.

\section{Analysis of Essential Oil by Gas Chromatography The essential oil was analyzed by using Shimadzu 2010 gas chromatograph equipped with FID using capillary column Rtx -wax, gas: Argon $(1 \mathrm{ml} / \mathrm{min})$, Temperature program $\left(60{ }^{\circ} \mathrm{C}-225{ }^{\circ} \mathrm{C}\right.$ at 5 $\left.{ }^{\circ} \mathrm{C} / \mathrm{min}\right)$, Injector temperature $\left(230{ }^{\circ} \mathrm{C}\right)$ and Detector temperature $\left(240{ }^{\circ} \mathrm{C}\right)$.}

\section{Determination of Physico-Chemical Parameters}

Physico - chemical parameters such as total ash content, acid insoluble and water soluble ash contents were determined for $\mathrm{MT}_{1}$ and $\mathrm{MT}_{2}$ of $O$. sanctum leaves collected from WP, NCP,SP and NP according to methods described below[12].

\section{Total ash}

Crucibles $(n=3)$ were cleaned, kept in the oven at $105{ }^{\circ} \mathrm{C}$ for $1 \mathrm{~h}$ and measured the empty crucible weights. Then, $2 \mathrm{~g}$ of accurately weighed sample was placed in a crucible and ignited. Then the sample with the crucible was kept in the muffle furnace (at $500-$ $600{ }^{\circ} \mathrm{C}$ ) until the sample turn into white color. Then it was cooled in the desiccator for $30 \mathrm{~min}$ and weighed without delay.

\section{Water soluble ash}

Previously ignited crucible with ash was boiled for $5 \mathrm{~min}$ after adding $5 \mathrm{ml}$ of distilled water and filtered by using a Whatman ashless filter paper. Same procedure was repeated thrice. Then the ashless filter paper containing water insoluble matter was ignited in the same crucible and kept in the muffle furnace at temperature of $450{ }^{\circ} \mathrm{C}$ for $15 \mathrm{~min}$. Then the residue was allowed to cool in a desiccator for $30 \mathrm{~min}$ and crucible containing water insoluble ash was weighed without delay.

\section{Acid insoluble ash}

Hydrochloric acid (2M, $5 \mathrm{ml}$ ) was added to the crucible containing total ash, covered with a watch glass and boiled gently for 5 minutes. The watch glass was rinsed with $5 \mathrm{ml}$ of hot water and added into the crucible. Same procedure was repeated thrice. Acid insoluble matter was collected on a Whatman ashless filter paper and washed with hot water until the filtrate becomes neutral. Then the filter-paper containing acid insoluble matter was transferred to the original crucible and dried on a hotplate and burned in gas cooker and ignited to constant weight at $450{ }^{\circ} \mathrm{C}$ in a muffle furnace. Then the residue was allowed to cool in a desiccator for $30 \mathrm{~min}$ and weighed without delay.

\section{STATISTICAL ANALYSIS}

All data were expressed as Mean \pm SEM. All statistical comparison compared through one-way analysis of variance (ANOVA), using Tukey's HSD post hoc test $(\mathrm{p} \leq 0.05)$.

\section{RESULTS AND DISCUSSION}

In the present study, phytochemical and physico-chemical comparison was carried out in between two monotypes ( $\mathrm{MT}_{1}$ and $\mathrm{MT}_{2}$ ) of $O$. sanctum collected from four locations [Western province (WP), North Central province (NCP) Southern province (SP) and North province (NP)] from the country at flowering stage. In Sri Lanka, only two monotypes (plants bearing green leaves and purple leaves) of $O$. sanctum were present. However, in India, other than green and purple 
monotypes, Rama and Shyama monotypes were found among different clusters across the phytogeographical regions [13].

Highest amount of essential oil content was present for both $\mathrm{MT}_{1}$ and $\mathrm{MT}_{2}$ of $O$. sanctum collected from SP (Table-1). However, amount of essential oil content in $\mathrm{MT}_{2}(2.1 \pm 0.2 \%)$ was greater than that of $\mathrm{MT}_{1}(1.5 \pm 0.2 \%)$ of SP. According to Dharmadasa and co-workers [11] percentage of essential oil content in $O$. sanctum aerial parts were in the range of $1.4-1.5 \%$. In contrast, volatile oil percentage of $O$ sanctum grown in India was in between $0.7 \%$ [14] and volatile oil $0.8 \%$ [15]. Essential oil composition of $O$. sanctum is given in Table 2 and in the present study, mainly focused on four prominent volatile compounds (eugenol, methyl eugenol , $\beta$ - elemene, $\beta$-caryophyllene and germacreneD) which known to present in $O$. sanctum. Methyl eugenol is the major compound in $O$. sanctum $[1,7]$ and reported to be the most effective naturally occurring male-fruit fly attractant [16, 17]. Overall results revealed that methyl eugenol was present in $O$. sanctum in a range of $0.2-66 \%$. Compared to the $\mathrm{MT}_{1}$ methyl eugenol content was higher in $\mathrm{MT}_{2}$ of $O$. sanctum collected from WP, NCP, SP and NP. The highest amount of methyl eugenol was present in $\mathrm{MT}_{2}$ of $O$. sanctum collected from WP and SP. The percentage of $\beta$-caryophyllene was in a range of $13.3-$ $29.9 \%$ in the entire tested $O$. sanctum and there was no marked difference among the $\mathrm{MT}_{1}$ and $\mathrm{MT}_{2}$ or with their location. The highest percentage of eugenol was contained in $\mathrm{MT}_{2}$ of $O$. sanctum and there is no significant dependency of the location. Further, it is very interesting to note that percentages of germacrene$\mathrm{D}$ and $\beta$-elemene were both higher in $\mathrm{MT}_{2}$ of $O$. sanctum in WP and SP respectively. Therefore, $\mathrm{MT}_{2}$ collected from SP was rich in methyl eugenol and $\beta$ elemene. Similar study was conducted to compare the two monotypes $(O$. sanctum Shyama and $O$. sanctum Rama) of $O$. sanctum grown in India and results revealed that percentages of methyl eugenol and ecaryophyllene were different among the two monotypes [18].

There was no significant difference in terms of total ash or water soluble ash or acid insoluble ash between $\mathrm{MT}_{1}$ and $\mathrm{MT}_{2}$ collected from four provinces of Sri Lanka (Table-3). The total ash usually consists of both physiologic ash and non-physiologic ash (eg.carbonates, phosphates, silicates and silica). Acid insoluble ash indicates contamination with silica, for example, earth and sand [19]. Further, we have collected $O$. sanctum leaves during the flowering stage and therefore, maturities of the leaves are in same age. Thus, chemical or physico-chemical variations are due to the geological or environmental factors in four provinces of Sri Lanka.

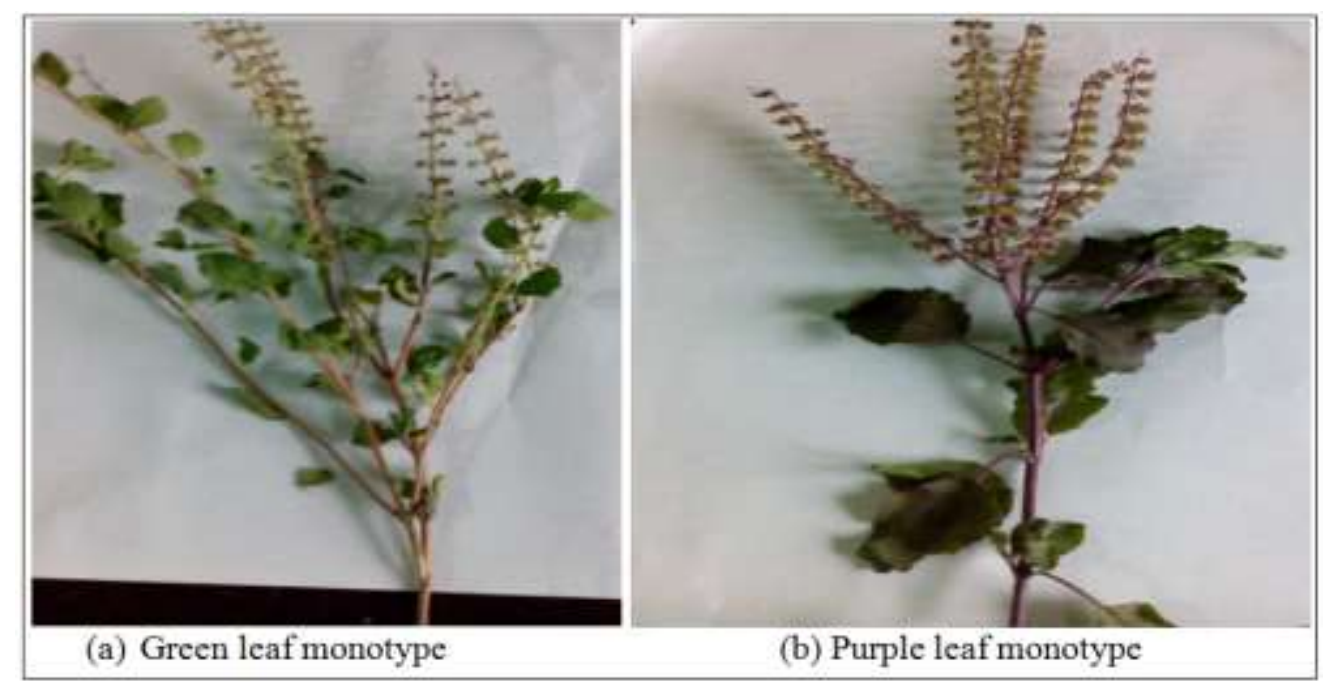

Plate-1: Green and purple leaf monotypes of Ocimum sanctum

Table-1: Percentages of volatile oil contents in green leaf variety $\left(\mathrm{MT}_{1}\right)$ and purple leaf variety $\left(\mathrm{MT}_{2}\right)$ of $O$ cimum sanctum grown in Sri Lanka

\begin{tabular}{|l|l|l|}
\hline Provinces & $\begin{array}{l}\text { Volatile oil content }(\%) \text { of } \\
\text { green variety }\left(\mathbf{M T}_{\mathbf{1}}\right)\end{array}$ & $\begin{array}{l}\text { Volatile oil content }(\%) \text { of } \\
\text { purple variety }\left(\mathbf{M T}_{\mathbf{2}}\right)\end{array}$ \\
\hline Western Province & $0.7 \pm 0.2^{\mathrm{b}}$ & $1.6 \pm 0.1^{\mathrm{b}}$ \\
\hline Southern Province & $1.5 \pm 0.2^{\mathrm{a}}$ & $2.1 \pm 0.2^{\mathrm{a}}$ \\
\hline North Central Province & $1.0 \pm 0.1^{\mathrm{b}}$ & $1.6 \pm 0.2^{\mathrm{b}}$ \\
\hline North Province & $0.6 \pm 0.3^{\mathrm{b}}$ & $1.4 \pm 0.2^{\mathrm{b}}$ \\
\hline
\end{tabular}

Data expressed as Mean \pm SEM, $n=6$

${ }^{\mathbf{a}, \mathbf{b}}$ Alphabetical superscripts in a column indicate significant differences between oil content of Ocimum sanctum grown in different provinces, $\mathrm{p}<0.05$ 
Table-2: Some selected volatile oil percentages of green leaf variety $\left(\mathrm{MT}_{1}\right)$ and purple leaf variety $\left(\mathrm{MT}_{2}\right)$ of Ocimum sanctum grown in Sri Lanka

\begin{tabular}{|l|l|l|l|l|l|}
\hline Specimen & Methyl eugenol \% & $\boldsymbol{\beta}$-Caryophyllene\% & Eugenol\% & \multicolumn{1}{|c|}{ Germacrene- D\% } & $\boldsymbol{\beta}$-Elemene\% \\
\hline \multirow{3}{*}{ Western Province } & $5.5-9.4\left(\mathrm{MT}_{1}\right)$ & $22.3-28.7\left(\mathrm{MT}_{1}\right)$ & $1.9-6.0\left(\mathrm{MT}_{1}\right)$ & $8.8-9.1\left(\mathrm{MT}_{1}\right)$ & $0.6-8.2\left(\mathrm{MT}_{1}\right)$ \\
\cline { 2 - 7 } & $0.2-66.0\left(\mathrm{MT}_{2}\right)$ & $20.5-28.5\left(\mathrm{MT}_{2}\right)$ & $5.2-6.8\left(\mathrm{MT}_{2}\right)$ & $3.8-11.6\left(\mathrm{MT}_{2}\right)$ & $0.6-13.0\left(\mathrm{MT}_{2}\right)$ \\
\hline \multirow{3}{*}{ Southern Province } & $0.8-0.5\left(\mathrm{MT}_{1}\right)$ & $13.3-21.6\left(\mathrm{MT}_{1}\right)$ & $0.6-4.6\left(\mathrm{MT}_{1}\right)$ & $3.3-10.2\left(\mathrm{MT}_{1}\right)$ & $1.9-8.8\left(\mathrm{MT}_{1}\right)$ \\
\cline { 2 - 7 } & $15.9-64.7\left(\mathrm{MT}_{2}\right)$ & $21.3-29.9\left(\mathrm{MT}_{2}\right)$ & $2.8-5.8\left(\mathrm{MT}_{2}\right)$ & $12.6-18.3\left(\mathrm{MT}_{2}\right)$ & $12.2-13.4\left(\mathrm{MT}_{2}\right)$ \\
\hline North Central Province & $7.2-7.4\left(\mathrm{MT}_{1}\right)$ & $19.7-24.8\left(\mathrm{MT}_{1}\right)$ & $5.3-6.1\left(\mathrm{MT}_{1}\right)$ & $7.6-12.3\left(\mathrm{MT}_{1}\right)$ & $0.6-2.8\left(\mathrm{MT}_{1}\right)$ \\
\cline { 2 - 7 } & $0.2-51.4\left(\mathrm{MT}_{2}\right)$ & $23.3-25.5\left(\mathrm{MT}_{2}\right)$ & $6.7-6.8\left(\mathrm{MT}_{2}\right)$ & $10.7-11.0\left(\mathrm{MT}_{2}\right)$ & $1.9-2.0\left(\mathrm{MT}_{2}\right)$ \\
\hline \multirow{2}{*}{ North Province } & $17.2-18.0\left(\mathrm{MT}_{1}\right)$ & $23.9-24.0\left(\mathrm{MT}_{1}\right)$ & $1.9-2.2\left(\mathrm{MT}_{1}\right)$ & $7.9-8.2\left(\mathrm{MT}_{1}\right)$ & $6.5-6.7\left(\mathrm{MT}_{1}\right)$ \\
\cline { 2 - 7 } & $31.9-32.1\left(\mathrm{MT}_{2}\right)$ & $27.2-27.4\left(\mathrm{MT}_{2}\right)$ & $5.0-5.5\left(\mathrm{MT}_{2}\right)$ & $7.5-8.5\left(\mathrm{MT}_{2}\right)$ & $7.4-7.8\left(\mathrm{MT}_{2}\right)$ \\
\hline
\end{tabular}

Data expressed as Mean \pm SEM, $n=6$

Table-3: Percentages of physico-chemical parameters of green leaf variety $\left(\mathrm{MT}_{1}\right)$ and purple leaf variety $\left(\mathrm{MT}_{2}\right)$ of Ocimum sanctum grown in Sri Lanka

\begin{tabular}{|l|l|l|l|l|}
\hline \multirow{2}{*}{ Provinces } & \multicolumn{3}{|l}{$\begin{array}{l}\text { Physico-chemical parameters of green } \\
\text { variety }\left(\mathbf{M T}_{\mathbf{1}}\right)\end{array}$} & $\begin{array}{l}\text { Physico-chemical parameters of purple } \\
\text { variety }\left(\mathbf{M T}_{\mathbf{2}} \text { ) }\right.\end{array}$ \\
\hline Western Province & Total ash & $11.6 \pm 0.8$ & Total ash & $10.2 \pm 0.5$ \\
\hline & Water soluble ash & $7.1 \pm 0.8$ & Water soluble ash & $6.6 \pm 0.7$ \\
\cline { 2 - 5 } & Acid insoluble ash & $\geq 0.01$ & Acid insoluble ash & $\geq 0.01$ \\
\hline Southern Province & Total ash & $10.5 \pm 0.7$ & Total ash & $9.8 \pm 0.5$ \\
\hline & Water soluble ash & $7.8 \pm 0.4$ & Water soluble ash & $6.0 \pm 0.7$ \\
\hline & Acid insoluble ash & $\geq 0.01$ & Acid insoluble ash & $\geq 0.01$ \\
\hline North Central Province & Total ash & $9.8 \pm 0.9$ & Total ash & $11.6 \pm 0.8$ \\
\hline & Water soluble ash & $7.6 \pm 0.4$ & Water soluble ash & $7.6 \pm 0.7$ \\
\hline & Acid insoluble ash & $\geq 0.01$ & Acid insoluble ash & $\geq 0.01$ \\
\hline North Province & Total ash & $10.1 \pm 0.4$ & Total ash & $10.0 \pm 0.8$ \\
\hline & Water soluble ash & $6.8 \pm 0.6$ & Water soluble ash & $6.0 \pm 0.5$ \\
\hline & Acid insoluble ash & $\geq 0.01$ & Acid insoluble ash & $\geq 0.01$ \\
\hline
\end{tabular}

Data expressed as Mean \pm SEM, $n=6$

\section{CONCLUSION}

An attempt was taken for the first time, to compare the phyto-chemical and physico-chemical differences between $\mathrm{MT}_{1}$ and $\mathrm{MT}_{2}$ of $O$. sanctum grown in four different geological areas of Sri Lanka. Methyl eugenol, the most important phyto-constituent is significantly highest in $\mathrm{MT}_{2}$ of $O$. sanctum than that of $\mathrm{MT}_{1}$. Therefore, overall results revealed that $\mathrm{MT}_{2}$ of $O$. sanctum collected from SP is more versatile in terms of oil content and chemical constituents.

\section{COMPETING INTERESTS DISCLAIMER}

Authors have declared that no competing interests exist. The products used for this research are commonly and predominantly use products in our area of research and country. Also, the research was not funded by the producing company rather it was funded by personal efforts of the authors.

\section{Authors' Contributions}

This work was carried out in collaboration among all authors and equally contributed for the research concept and work plan. Author HRDF conducted the experiments and Author LDAMA and HRDF prepared the manuscript. Author WMSSKK provided relevant literature. All authors read and approved the final manuscript.

\section{REFERENCES}

1. Baseer, M., \& Jain, K. (2016). Review of Botany, Phytochemistry, Pharmacology, Contemporary applications and Toxicology of Ocimum sanctum. International Journal of Pharmacy \& Life Sciences, 7(2):4918-4929.

2. Philip, S. A., \& Purushotham, S. (2018). Ocimum sanctum: An Advent as a local drug delivery agent in the management of periodontal disease. International Journal of Innovative Science and Research Technology. 3(11):765-768.

3. Basu, K. (1987). Indian Medicinal Plants, $2^{\text {nd }}$ edition, International Book Distributors, Dehradun. 1965-1966.

4. Sharma, P. C., Yelne, M. B., \& Dennis, T. J. (2005). Data base on medicinal plants used in Ayurveda. 2, Delhi, CCRAS, Reprint.

5. Rahman, S., Islam, R., Kamruzzaman, M., Alam, K., \& Jamal, A. M. (2011). Ocimum sanctum L.: A review of phytochemical and pharmacological profile (No. RESEARCH).

6. Panda, S., \& Tripathy, S. (2018). A review on pharmaceutical consideration of Ocimum sanctum. International Journal of Research Ayurveda Pharmacy. 9(3):133-134.

7. Vina, A., \& Murillo, E. (2003). Essential oil composition from twelve varieties of Basil (Ocimum spp) grown in Colombia. Journal of Brazilian Chemical Society. 14:744-749. 
8. Mohan, L., Amberkar, M. V., \& Kumari, M. (2011). Ocimum sanctum Linn (Tulsi)—an overview. Int J Pharm Sci Rev Res, 7(1), 51-53.

9. Kavyashree, M. R., Harini, A., Hegde, P. L., \& Pradeep, D. (2019). A review on Tulsi (Ocimum sanctum Linn). Drug Delivery and Therapeutics. 9(2-s): 562-569.

10. Dharmadasa, R. M., Siriwardhane, D. A. S., Samarasinghe, K., Rangana, S. H. C. S., Nugaliyadda, L., Gunawardane, I., \& Aththanayake, A. M. L. (2015). Screening of two Ocimum tenuiflorum L.(Lamiaceae) morphotypes for their morphological characters, essential oil composition and fruit fly attractant ability. World, 3(1), 1-4.

11. Abeywardhana, K. W., Abeysinghe, D. C., Dharmadasa, R. M., \& Aththanayake, A. M. L. (2014). Determination of Optimum Maturity Stage for Ocimum sanctum L. Grown under Different Growing Systems in Terms of Therapeutically Active Secondary Metabolites. World Journal of Agricultural Research, 2(4), 159-162.

12. WHO. (1998). Quality control methods for medicinal plant materials. World Health Organization, Geneva.

13. Malav, P., Pandey, A., Bhatt, K. C., Krishnan, S. G., \& Bisht, I. S. (2015). Morphological variability in holy basil (Ocimum tenuiflorum L.) from India.Genetic Resources and Crop Evolution, 62(8), 1245-1256.
14. Uma, D. P. (2001). Radioprotective, anticarcinogenic and antioxidant properties of the Indian holy basil, Ocimum sanctum (Tulasi). Indian Journal of Experimental Biology. 39:185190.

15. Dohare, S. L., Shuaib, M., Ahmad, M. I., \& Naquvi, K. J. (2012). Chemical composition of volatile oil of Ocimum sanctum Linn. International Journal of Biomedical and Advance Research. 3(2):129-131.

16. Wee, S. L., Hee, A. K. W., \& Tan, K. H. (2002). Comparative sensitivity to and consumption of methyl eugenol in three Bactrocera dorsalis (Diptera: Tephritidae) complex sibling species. Chemoecology. 12:193-197.

17. Vargas, R., Shelly, T. E., Leblanc, L., \& Piñero, J. C. (2010). Chapter twenty-three-recent advances in methyl eugenol and cue-lure technologies for fruit fly detection, monitoring and control in Hawaii. Vitamins and Hormones. 83:575-595.

18. Awasthi, P. K., \& Dixit, S. C. (2007). Chemical composition of Ocimum sanctum Shyama and Ocimum sanctum Rama oils from the plains of Northern India. Journal of essential oil bearing plants. 10(4):292-296.

19. Mukherjee, P. K. (2002). Quality Control of Herbal Drugs. New Delhi, India: Business Horizons. 